\title{
Transient Stability Improvement of IEEE 9-Bus System Using Static Var Compensator
}

\author{
Manish Shrivastava ${ }^{1}$, Vinay Prakash ${ }^{2}$, Vishal Kaushik ${ }^{3 *}$, Vivek Kumar Upadhyay ${ }^{4}$ \\ 1,2,3,4 Department of Electrical and Electronics Engineering, Galgotias College of Engineering \& Technology, \\ Greater Noida, India
}

\begin{abstract}
With increase in power demand over the last few decades, there has been a great expansion in power generation $\&$ transmission. But due to various disturbances, improper loading and environmental conditions the power systems are working near their stability limits which have become a power-transfer limiting factor. This in turn poses a threat to the stability of the system. Transient stability has been considered as one of the most important stability for a power system. In this paper Static VAR Compensator (SVC) has been discussed for reactive power control and hence improvement of transient stability and voltage profile. This paper incorporates IEEE-9 BUS test system with SVC controller using MATLAB Simulation.
\end{abstract}

Keywords: IEEE 9-BUS system, MATLAB software, power system stability, power system stabilizer (PSS), Static Compensator VAR.

\section{Introduction}

Power transmission networks of present are becoming progressively more stressed due to increasing request and, limitations on erecting new improved transmission cable. Such stressed/loaded systems pose a risk of instability after any failure. FACTS devices have proven very well-reasoned in a busy hauling system to make higher standard use of prevailing facilities without losing the expected balance. FACTS such as Steady AC Compensator use the vanguard of electronic on/off devices in power transmission complex to control volt and watt flow \& have a salient role in stability \& in the response to transients' disturbances in interconnected power systems [1], [2], [16].

Due to the fact that the volumetric power transmission is swelling, the extension of the energy transferring capacity is limited. In inclusion to outdated transmission networks, fast and reliable transmission management is required. Power systems have been often exposed to low frequency electromechanical vibrations from electrical noise and interconnections between large power systems.

The oscillations in rotor of generator leads to oscillations in other variables in the power supply system (bus voltage, real and Var power of the transmission lines, etc.) which block the possibility of power transmission and compromise the safety of the system reducing the smooth working of fuel system.

Less frequency oscillations is divided into local and interzonal. The oscillation of the local mode is usually in the range of 1 to $2 \mathrm{~Hz}$ and accounts the oscillations of a group of synchronous alternators related to whole system, while interzonal mode is usually in the range of $0.1-1 \mathrm{~Hz}$ and consists in fluctuations between groups of generators. Typically, PSS are applied on selected specific alternators to effectively dampen local fluctuations [10]-[15].

Rapid advances in power electronics have expanded the power industry's ability to improve grid stability through the use of the FACTS. In addition to their ability to manage the transmission network \& enlarging transfer size, FACTS even provide an altogether new way to reduce power network fluctuations. As per the IEEE, a FACTS instrument is "a system of power electronics and various static instruments which controls few or more parameters of an AC transfer system to improve governable and power transfer capability." The FACTS was originally designed to address the growing systemic problems due to restrictions on the construction of transmission lines in order to add to the growing export \& / or import of electricity \& transactions between facilities. FACTS equipment includes variety of techniques which improve safety, capacity \& movement of power transfer. Using FACTS instruments, power networks will be able to expand the volume of the present energy transfer network while supporting or making better the operational constraints required for the system stability [2]-[4].

Since the PSS was used to dampen local vibration modes, the VAR Compensator, one of the FACTS instruments, was brought into use as an additional restrainer to make momentary oscillation stable $\&$ dampen system energy fluctuations. These controllers are designed using the traditional method, which is based on a literal model for simplicity [17], [18].

\section{Power System Stability}

Power system stability refers to the system's ability to pay back to its steady state in the event of an outage. As stated earlier, the potential is originated by synchronous generators which employ in sync among the system. A generator is said to be synchronized to the bus-bar if all are having the proportional frequency, potential \& angle sequence. Therefore, we could substitute PSS as the power system's aptitude to roll back to a 
steady state without loss of synchronism. PSS is extended into Steady State Stability, Dynamic Stability \& Transient Stability as shown in Figure 1, [6], [7], [9], [16].

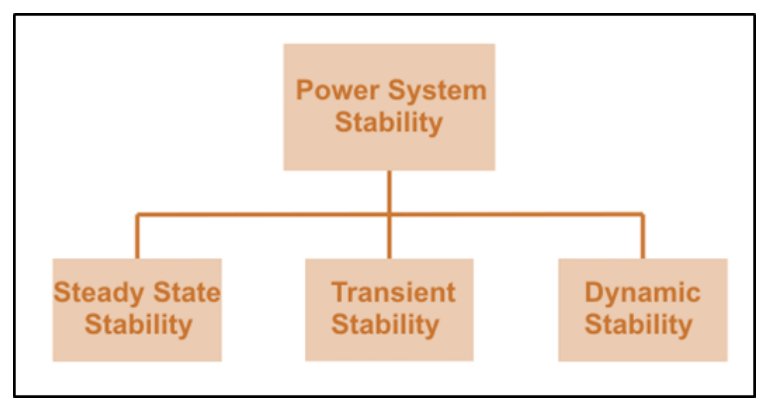

Fig. 1. Classification of stability of power system

\section{A. Steady State Stability}

Steady-state stability studies are limited to micro and slow commute in state of operation. We mainly concentrate on retaining bus potential not far from to their formal values. It as well ensures, the phase angles b/w 2 buses aren't excessive, \& overload checks are performed on power system gadget and transfer cable. These objectives are performed using potential flow studies. [7], [9].

\section{B. Transient Stability}

Includes examination of fuel system after any major outage. Due to the large deflection of synchronous generator, the machine's power angle or load angle alter due to the abrupt acceleration of the rotatory rod. Therefore, it can be said that the purpose of the transient stability test is to determine to come through the load angle back to a constant worth after the noise has been removed or not [11], [13].

The system may suffer malfunctions due to sudden load removal, line switching operations; system malfunction, sudden disconnection of the line, etc. Transient resistance is considered when planning the installation of new transmission and generation systems. The rotation equation describes the behavior of synchronous machines such as alternators during transient disturbances.

\section{Dynamic Stability}

The ability of a power system to retain its solidity under small continuous disruption is studied in terms of dynamic solidity and is also familiar as weak signal solidity. These micro disruptions are often due to accidental shifts in loads and originating levels. In a submerged power system, these accidental fluctuations can guide to very great failures as they can force a steady increase in the rotor angle.

\section{Static Var Compensator}

Static Var arrangements are widely used in power transmission systems for a variety of reasons. One of the most important reasons for using SVC is to quickly check the voltage at the weak points of the network. They can be installed in the middle of power lines or at the ends of a line. A static reactive power equalizer is primarily a parallel variable energy synchronous device whose $\mathrm{o} / \mathrm{p}$ signal altered to transfer inductive or capacitive flow of electrons to the system to control reactive power and voltage in the electrical network.[9][16]. The FC-TCR type is one of the most commonly used SVC configurations where a FC is applied in shunt with a TCR. The compensator connected in an FC-TCR model is shown in Figure 2. Compensator is fixed to a coupling T/F, which is then fixed with the $\mathrm{AC}$ bus, whose potential is required to be monitored.

The SVC voltage is regulated at its ends by altering the value of Var energy taken or fed into the energy system. If the total system voltage is below the required level, the compensator provides capacitive power, while if the network potential is higher than the required level, it draws reactive power from the grid (inductive SVC).

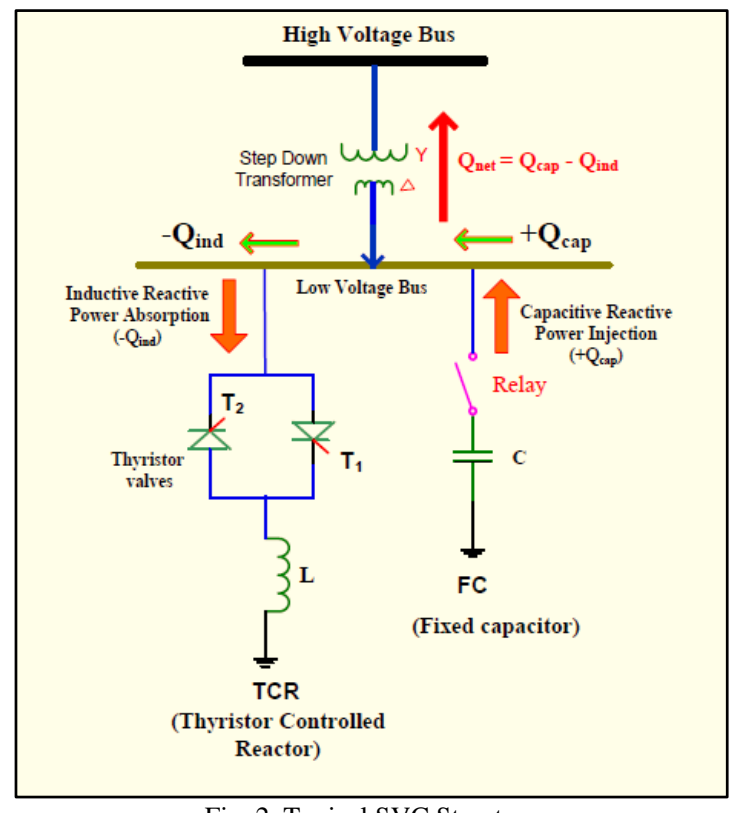

Fig. 2. Typical SVC Structure

The change in Var energy is done by changing combination of 3 phase capacitors and inductors connected to the second coil of the coupling $\mathrm{T} / \mathrm{F}$. Every given combination of capacitors is turned on and off by three thyristor switches and is therefore also called a thyristor capacitor or TSC. Reactors can be phase controlled (TCR) or angle switched (TSR) [12].

It is an impedance controlled device in which thyristor valves, connected end-to-end, are employed in controlling the rate of flow of charge through the reactor. The development of HVDC technology has led to a spinoff, which here is the application of thyristor valve technology in SVC. The notable dissimilarity is that the kind of diode valves used in the SVC are marked at lesser voltages because the Var compensator is fixed with the (EHV) line via a distribution T/F or fixed to the third coil of a power T/F.

The compensator connected in the TSC-TCR configuration is shown in Figure 3. The above figure clearly mentions that TSC and TCR are fixed with the second coil of the step-down $\mathrm{T} / \mathrm{F}$. The HPF and tuned filters are also parallelly shunted to fulfill Var power at the first harmonic. A potential transformer is employed to extract the potential signal from the high voltage 
bus of the SVC [12], [13].

At the moment of the cycle, when the potential through the plug is least \& +ve, the TSC is altered by 2 special diode controllers connected together. It gives $\mathrm{o} / \mathrm{p}$ in minimal altering disruption. TSC doesn't create steady oscillations. In TSCs, when the gate train oscillations are interrupted, the thyristor gets off because the rate of flow of charge flowing into \& out of them drops below the held current.

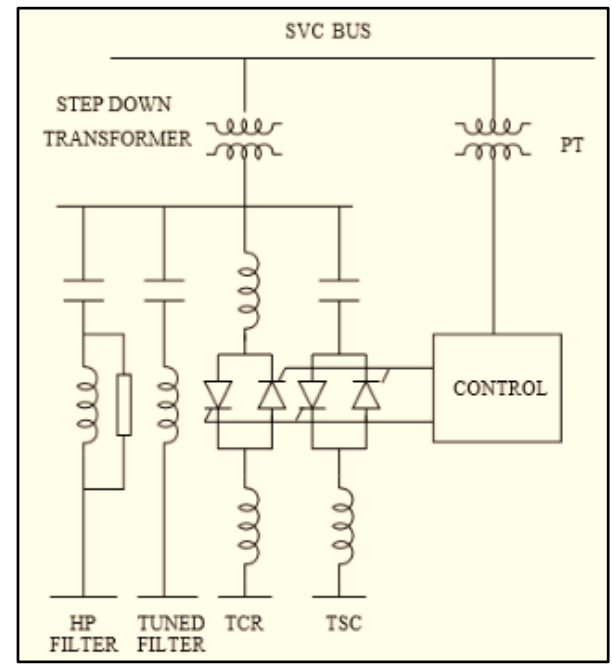

Fig. 3. Typical SVC (TSC-TCR) System

\section{Simulation and Results}

\section{A. Single Line Diagram of 9 BUS System}

of a power system. MATLAB software is used to perform simulations and analyzes. Figure 4 shows a single-line diagram of an IEEE-9Bus system.

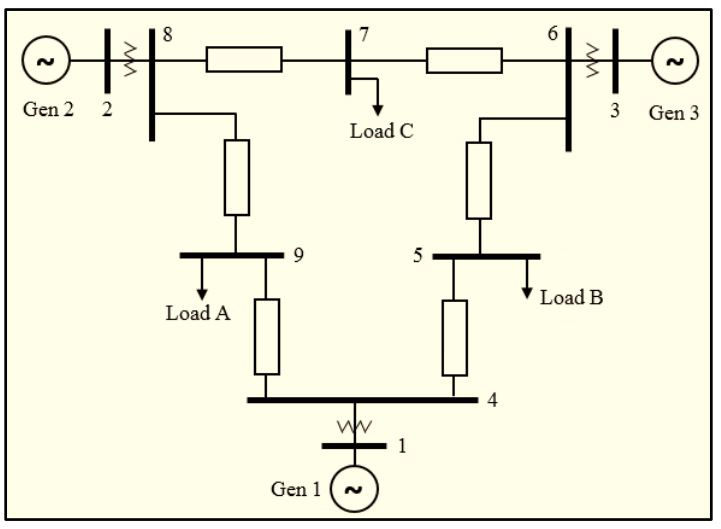

Fig. 4. IEEE-9 BUS System Single Line Diagram

The actual simulation model consists of 3 synchronous generators \& three power transformers of which 2 are of 5000MVA and 1 is of 1000MVA (it is possible to operate 2 transformers with different MVA ratings in parallel if they have the same primary/secondary voltage ratings and the winding polarities are in phase i.e. voltages are in phase and balanced), a transmission line network of 1135KM, three loads, 9 buses, a three phase fault occurring at bus 8 and a SVC block (FC-TCR type). The simulation is run for about $0.2 \mathrm{sec}$. The actual simulation model of the proposed system with and without SVC is shown in Figure $5 \& 6$.

This article uses IEEE-9BUS to analyze the transient stability

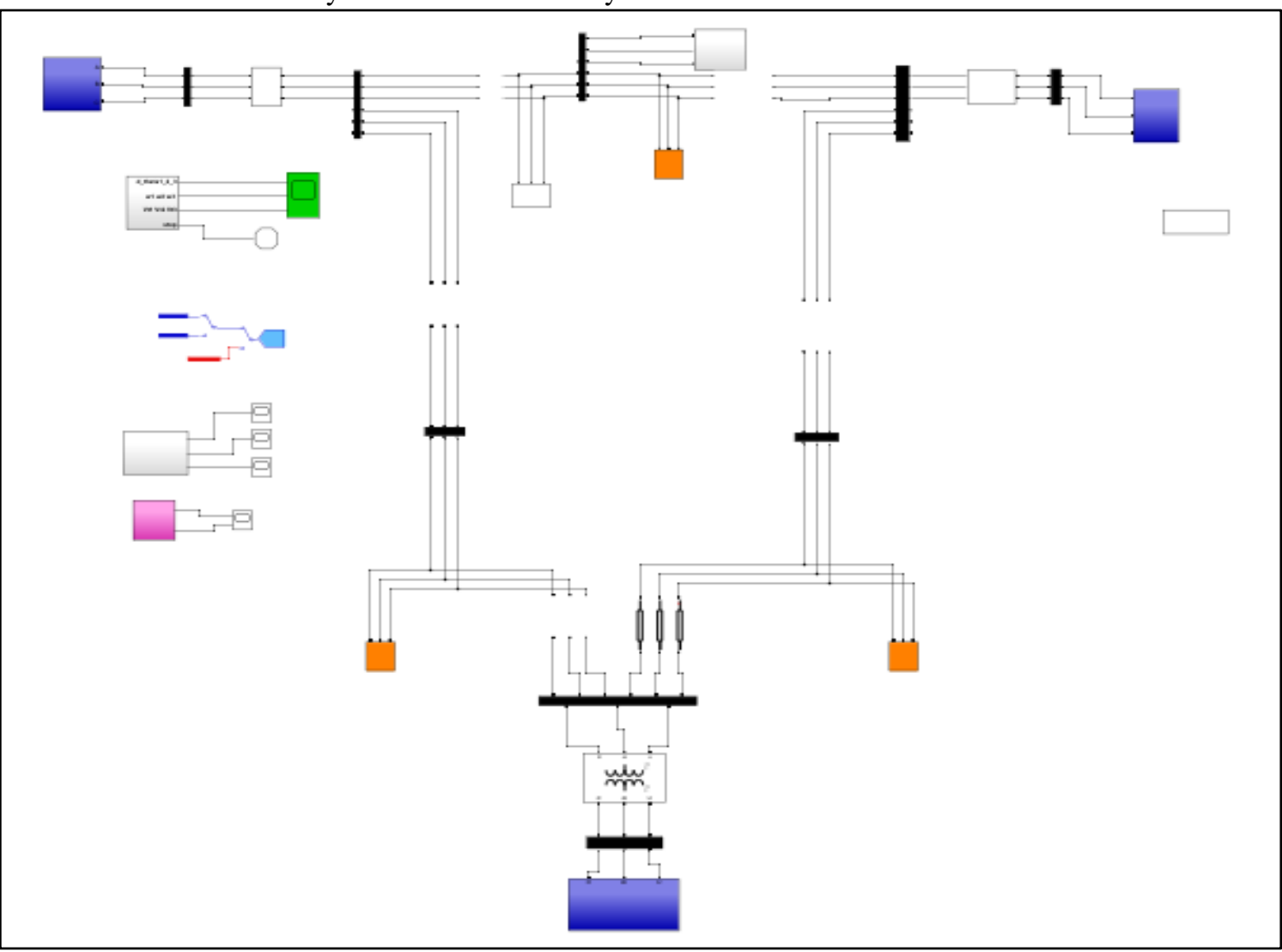

Fig. 5. 9 Bus system simulation model with SVC 


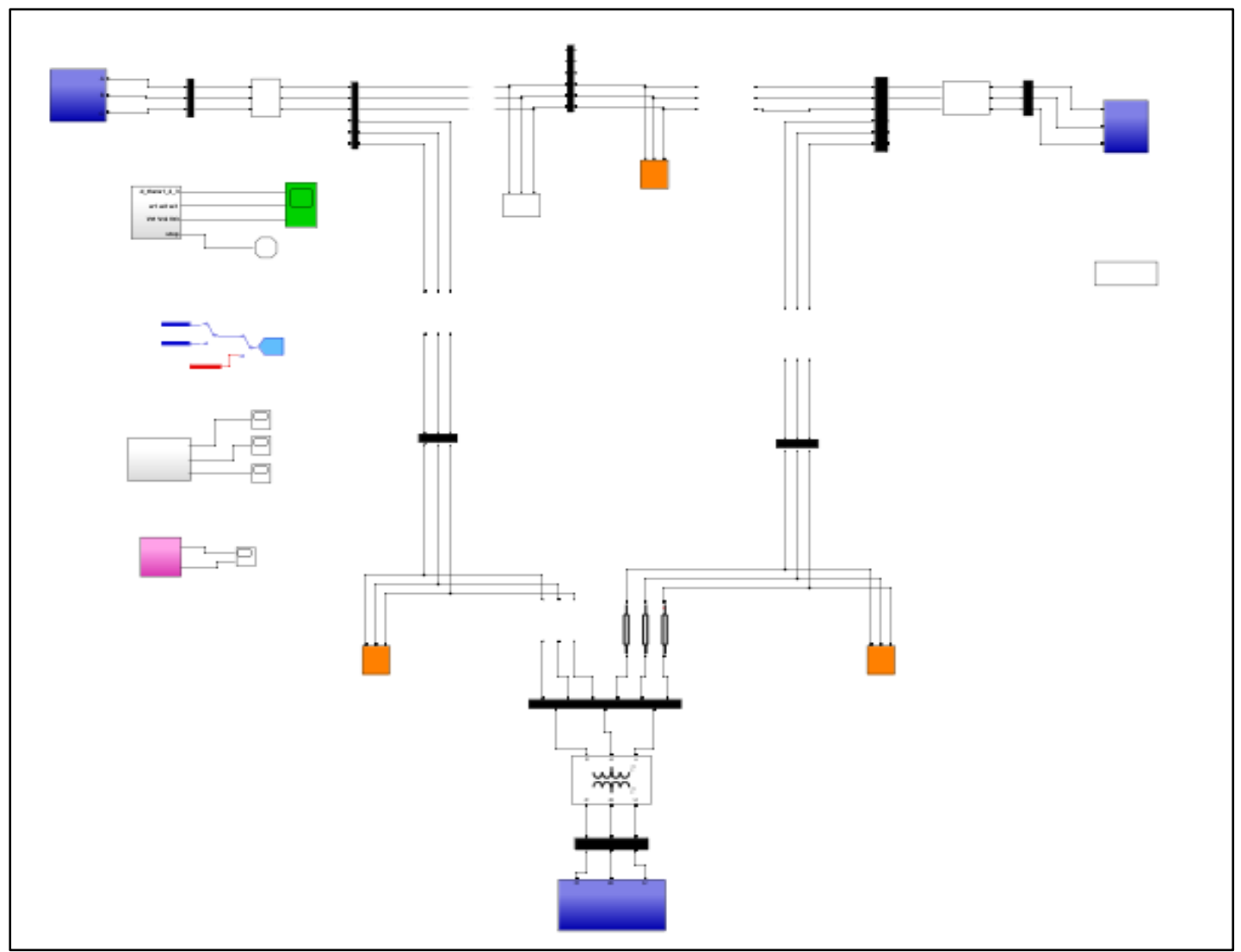

Fig. 6. 9 Bus system simulation model without SVC

\section{Results}

A. Voltage Waveforms for Various Loads with SVC
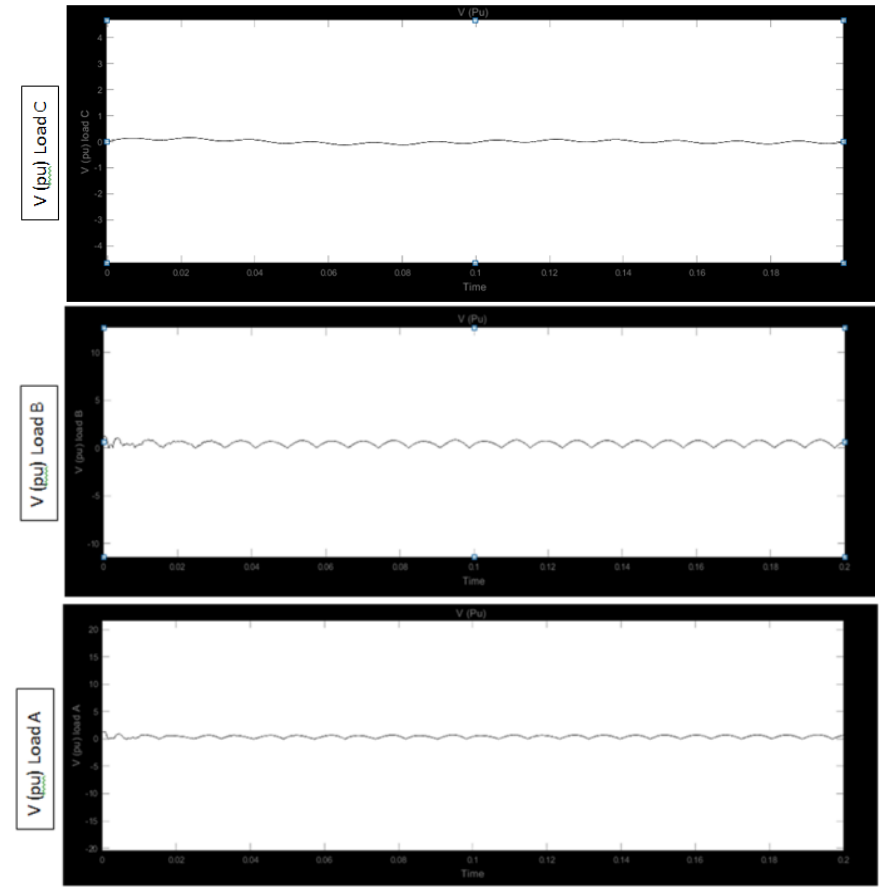

Fig. 7. Voltage waveforms for various loads with SVC
B. Real and Reactive Power Waveforms for power system with $S V C$

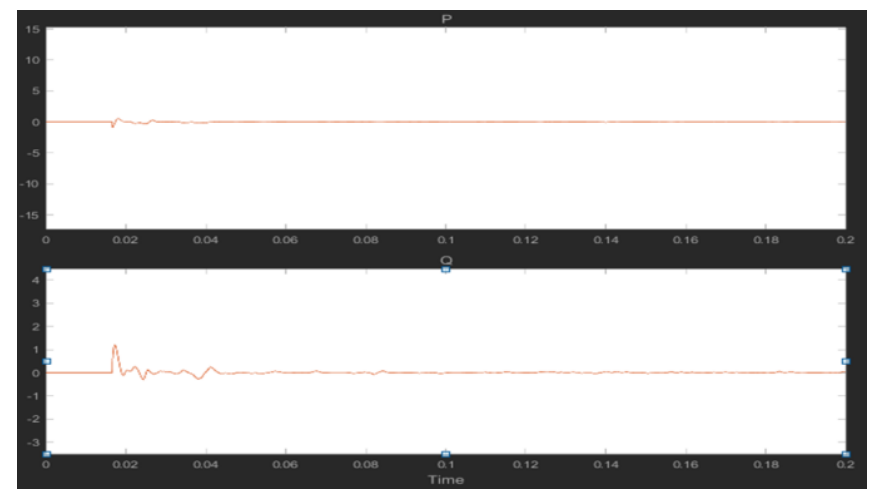

Fig. 8. Real and Reactive Power waveforms for power system with SVC

C. Voltage Waveforms for Various Loads without SVC

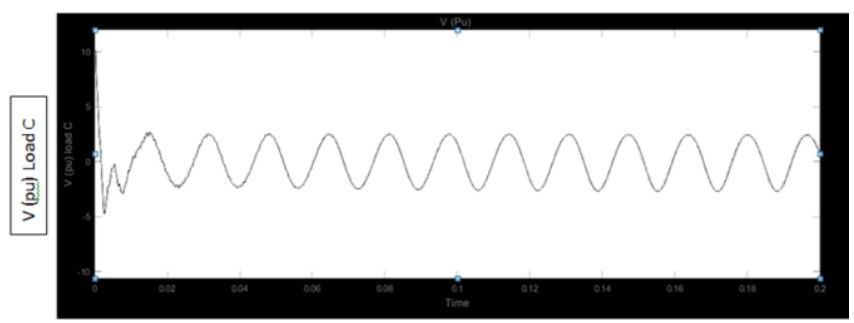




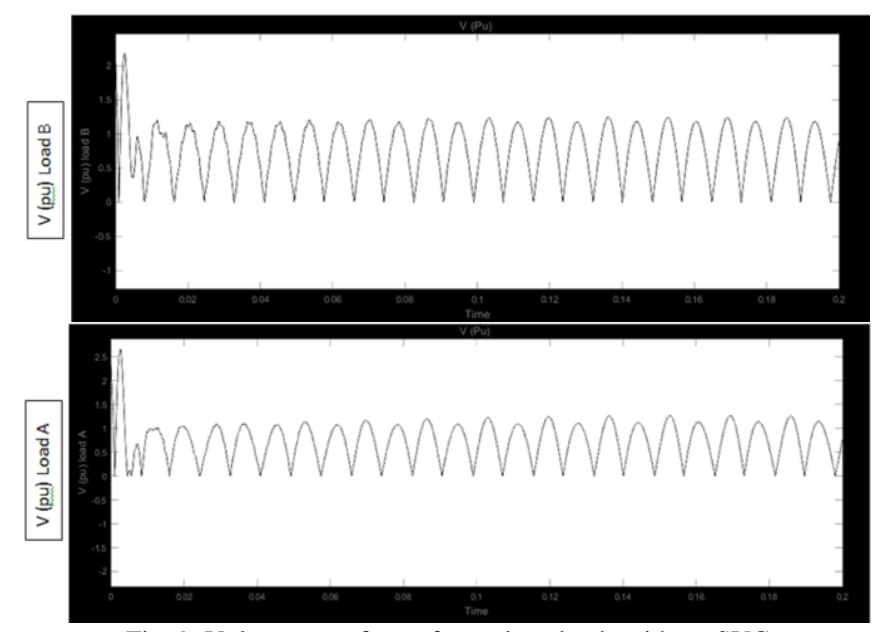

Fig. 9. Voltage waveforms for various loads without SVC

D. Real and Reactive Power Waveforms for power system without $S V C$

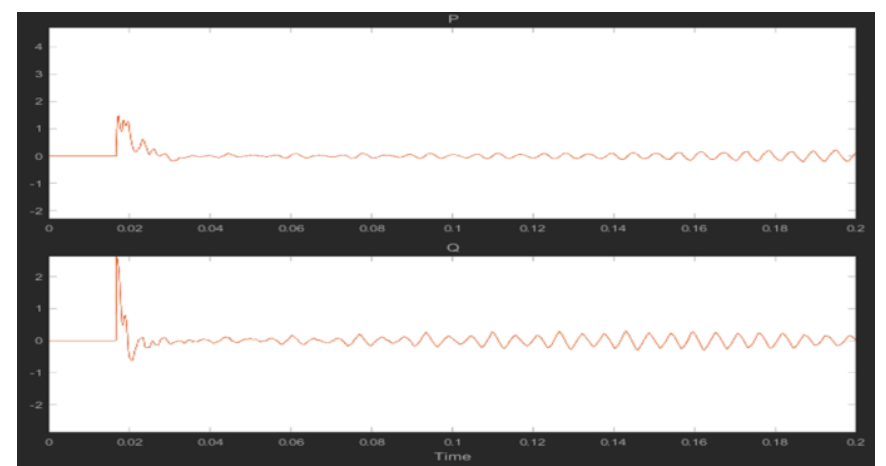

Fig. 10. Real and Reactive Power waveforms for power system without SVC

\section{Conclusion}

In this article, a power system is modeled with and without a VAR Static Compensator (SVC) to study the effect of transient stability and how it is attenuated using SVC. Looking at the results, we can clearly see that transients are very significant without SVC, while they are almost attenuated using SVC. Therefore, we can conclude that transient stability of the energy network under different loads greatly improves by the SVC.

\section{References}

[1] L. Gyugi and E. R. Taylor, Jr., "Characteristics of static, thyristor controlled shunt compensator for power transmission system applications," IEEE Trans. PAS, vol. 99, pp. 1795-1804, 1980.

[2] L. Gyugyi, "Fundamentals of thyristor-controlled static VAR compensators in electric power system applications," Symposium on Static VAR Compensators, IEEE/PES 1987 Winter Meeting.

[3] K. L. Liou and Y. Y. Hsu, "Damping of generator oscillations using static VAR compensators," IEEE Trans. AES, Vol. 22, pp. 605617, 1986.

[4] Swaroop Kumar, Nallagalva, Mukesh Kumar Kirar and Ganga Agnihotri, "Transient Stability Analysis of the IEEE 9-Bus Electric Power System", International Journal of Scientific Engineering and Technology, Volume No.1, July 2012.

[5] IEEE Power Engineering Society/CIGRE, "FACTS Overview", Publication 95 TP 108, IEEE Press, New York, 1995.

[6] Ramlal Das and D. K. Tanti, "Transient stability of 11-bus system using SVC and improvement of voltage profile in transmission line using series compensator", American Journal of Electrical Power and Energy Systems, 2014.

[7] P. Kundur, "Power System Stability and Control", McGraw-Hill, Inc., New York, 1994.

[8] Lerch, D. Povh, and L. Xu, "Advanced SVC Control for Damping Power System Oscillations," IEEE transactions on Power Systems, Vol. 6, No. 2, pp. 524-535 May 1991.

[9] N.G. Hingorani and L. Gyugyi, "Understanding FACTS: concepts and technology of flexible AC transmission systems," IEEE Press, New York, 2000.

[10] S. Panda and N.P. Padhy, "Power System with PSS and FACTS Controller Modeling, Simulation and Simultaneous Employing Genetic Algorithm," International Journal of Electrical and Electronics Engineering, pp.9-18, 2007.

[11] S. Gilbert, "transient stability of a two-machine transmission system with power system stabilizers (PSS) and Static Var Compensator (SVC)," Hydro-Québec, SimPowerSystems (Guid's), MathWork, MATLAB Simulink version 7.2.0, 2010.

[12] Saadat, H., 2002. Power System Analysis. Tata McGraw- Hill.

[13] Acha. E, Agelidis. V.G, Anaya-Lara. O, Miller. T.J.E (2002): Power Electronic Control in Electrical Systems" 451 pp. Chap 6 \& 9. Newnes Publisher.

[14] J. E. R. Alves, Jr., L. A. S. Pilotto, and E. H. Watanabe, "ThyristorControlled Reactors Nonlinear and Linear Dynamic Analytical Models," IEEE Trans. Power Deliv., vol. 23, no. 1, pp. 338-346, Jan. 2008.

[15] E. Zhijun, K. W. Chan, and D. Z. Fang, "Hybrid Simulation of Power Systems with Dynamic Phasor SVC Transient Model," 2007, pp. 16701675.

[16] Rathnasagar Rangu, and Poonam Upadhyay "Study of Transient Stability Improvement of IEEE 9-Bus System by using SVC", International Journal of Engineering Trends and Technology, vol. 27, no. 3, pp. 162166, September 2015.

[17] I. Kamwa, R. Grondin and G. Trudel, "IEEE PSS2B versus PSS4B: the limits of performance of modern power system stabilizers," in IEEE Transactions on Power Systems, vol. 20, no. 2, pp. 903-915, May 2005,

[18] O. Benaissa, S. Hadjeri, S. Zidi, "Impact of PSS and SVC on the Power System Transient Stability", Advances in Science, Technology and Engineering Systems Journal, vol. 2, no. 3, pp. 562-568, 2017. 